Article

\title{
Development of Mushroom-Based Cosmeceutical Formulations with Anti-Inflammatory, Anti-Tyrosinase, Antioxidant, and Antibacterial Properties
}

\author{
Oludemi Taofiq ${ }^{1,2,3}$, Sandrina A. Heleno ${ }^{1,3}$, Ricardo C. Calhelha ${ }^{1}$, Maria José Alves ${ }^{4}$, \\ Lillian Barros ${ }^{1}$, Maria Filomena Barreiro ${ }^{3}$, Ana M. González-Paramás ${ }^{2}$ \\ and Isabel C. F. R. Ferreira ${ }^{1, *}$ \\ 1 Mountain Research Centre (CIMO), ESA, Polytechnic Institute of Bragança, Campus de Santa Apolónia, \\ 1172, 5300-253 Bragança, Portugal; taofiq.oludemi@ipb.pt (O.T.); sheleno@ipb.pt (S.A.H.); \\ callelha@ipb.pt (R.C.C.); lillian@ipb.pt (L.B.) \\ 2 GIP-USAL, Unidad de Nutrición y Bromatología, Faculty of Pharmacy, University of Salamanca, \\ Campus Miguel de Unamuno, 37007 Salamanca, Spain; paramas@usal.es \\ 3 Laboratory of Separation and Reaction Engineering (LSRE), Associate Laboratory LSRE/LCM, \\ Polytechnic Institute of Bragança, Campus de Santa Apolónia, 1134, 5301-857 Bragança, Portugal; \\ barreiro@ipb.pt \\ 4 School of Health, Polytechnic Institute of Bragança, Av. D. Afonso V, 5300-121 Bragança, Portugal; \\ maria.alves@ipb.pt \\ * Correspondence: iferreira@ipb.pt; Tel.: +351-273-303-219; Fax: +351-273-325-405
}

Academic Editor: Derek J. McPhee

Received: 5 September 2016; Accepted: 11 October 2016; Published: 14 October 2016

\begin{abstract}
The cosmetic industry is in a constant search for natural compounds or extracts with relevant bioactive properties, which became valuable ingredients to design cosmeceutical formulations. Mushrooms have been markedly studied in terms of nutritional value and medicinal properties. However, there is still slow progress in the biotechnological application of mushroom extracts in cosmetic formulations, either as antioxidants, anti-aging, antimicrobial, and anti-inflammatory agents or as hyperpigmentation correctors. In the present work, the cosmeceutical potential of ethanolic extracts prepared from Agaricus bisporus, Pleurotus ostreatus, and Lentinula edodes was analyzed in terms of anti-inflammatory, anti-tyrosinase, antioxidant, and antibacterial activities. The extracts were characterized in terms of phenolic acids and ergosterol composition, and further incorporated in a base cosmetic cream to achieve the same bioactive purposes. From the results obtained, the final cosmeceutical formulations presented $85 \%-100 \%$ of the phenolic acids and ergosterol levels found in the mushroom extracts, suggesting that there was no significant loss of bioactive compounds. The final cosmeceutical formulation also displayed all the ascribed bioactivities and as such, mushrooms can further be exploited as natural cosmeceutical ingredients.
\end{abstract}

Keywords: cosmeceutical formulation; skin aging; mushrooms extracts; anti-inflammatory; anti-tyrosinase; antioxidant; antibacterial

\section{Introduction}

Skin aging is caused by an intrinsic or natural mechanism affecting the skin and other body organs related to hormonal changes occurring with age, and by extrinsic mechanisms associated with ultraviolet radiation exposure, which causes free radical species generation [1]. Reactive oxygen species (ROS) are responsible for inducing the activator protein-1 (AP-1), a transcription factor that promotes collagen and elastin breakdown by up regulation of the matrix metalloproteinases (MMPs) [2] 
This environmental stress generated from ROS and reactive nitrogen species (RNS), combined with increased secretion of inflammatory mediators and enzyme expression (e.g., collagenase and elastase), causes inflammation and decreases the tensile strength and elasticity of the skin [3]. Also in the antimicrobial domain, the incidence of skin and soft tissue infections is growing as a consequence of increasing bacteria resistance to drugs in a wide clinical spectrum [4].

Natural ingredients for skin care are becoming popular due to their protective and defensive role against generation of free radicals and reduced production of oxidative enzymes, such as inducible nitric oxide synthase (iNOS) associated with inflammation and inflammatory diseases; collagenase and elastase that usually cause degradation of the extracellular matrix of the skin; and tyrosinase, the enzyme that catalyzes the most important step in melanin biosynthesis [5]. Thus, an increasing interest in finding natural sources able to inhibit these enzymes, and using them as potential cosmetic ingredients in the design of creams or lotions for topical application is an interesting topic [6].

Cosmeceutical formulations containing bioactive ingredients-such as phytonutrients, microbial metabolites, dairy products, minerals, and animal proteins-displaying medical-drug like benefits able to improve the structure, function, and appearance of the skin, are becoming more and more appellative solutions [7].

Particularly, mushrooms, which are recognized as nutritionally important foods and reported as having important medicinal benefits, are slowly finding their way into the cosmetic industry in cosmeceutical applications, either as creams, lotions, or ointments [7]. Agaricus bisporus (J.E.Lange) Imbach, Lentinula edodes (Berk.) Pegler, and Pleurotus species are the most cultivated mushrooms worldwide, with a commercial production projected to increase significantly in the coming years [8]. A. bisporus has been known to show medicinal potential related with antitumor, antimicrobial, immunomodulatory, anti-inflammatory, and antioxidant properties [9]. L. edodes, popularly known as "shiitake", has been reported to halve the proliferation of tumor cells and to strengthen the immune system [10]. This mushroom has several bioactive compounds such as L-ergothioneine and lentinan known to exert strong antioxidant [11,12] and anti-inflammatory [13] activities, respectively. Pleurotus ostreatus (Jacq. ex Fr.) P. Kumm., has also attracted attention due to its content in polysaccharides, proteins, organic acids, vitamins, and minerals [14], being reported as having anti-inflammatory [15], antioxidant [16], immunomodulatory, antimicrobial, and antitumor effects [17]. All these aforementioned medicinal properties of mushroom extracts and related bioactive constituents, reinforce the interest in these natural matrices for cosmetic applications.

Some mushroom-based cosmetics can be found in the market; examples include Aveeno Positively Ageless, which contains shitake (L. edodes) extract (www.aveeno.com) used to improve skin's health; Sekkisei Cream containing Cordyceps sinensis (Berk.) Sacc., extract (www.coracosmetics.com), used to strengthen skin's natural defense system and to suppress melanin production, thereby correcting hyperpigmentation; Embellir Refresh Massage that contains Ganoderma lucidum (Curtis) P. Karst extract (www.menard-cosmetic.com) used as a cleansing and massage cream and also as an efficient anti-aging skin care product.

The present study aimed to evaluate the cosmeceutical potential of A. bisporus, L. edodes, and $P$. ostreatus ethanolic extracts through the assessment of their anti-inflammatory, anti-bacterial, antioxidant, and anti-tyrosinase activities, and further incorporation in a cosmetic base cream. The bioactive properties of the final formulations were confirmed and related with the chemical ingredients present in the extracts, namely with phenolic acids and ergosterol.

\section{Results and Discussion}

\subsection{Chemical Characterization of the Mushroom Ethanolic Extracts}

The chemical composition of the mushroom extracts is presented in Table 1. P. ostreatus showed the highest content in phenolic acids and cinnamic acid (related compound), followed by L. edodes and, finally, A. bisporus. The highest content in P. ostreatus is due to the contribution of cinnamic and $p$-hydroxybenzoic acids, found in much higher amounts in this species, followed by $p$-coumaric acid. 
Protocatechuic acid was only identified in L. edodes, while A. bisporus only revealed the presence of cinnamic acid.

The results are consistent with the ones published by Taofiq et al. [15] that reported the presence of all those three phenolic acids in P. ostreatus ethanolic extract obtained by maceration and only cinnamic acid in A. bisporus. Carneiro et al. [18] described the presence of vanillic and $p$-coumaric acids in methanol/water (80:20, v/v) extract of L. edodes from Brazil. The differences between the used extraction procedures and mushroom origin can justify the dissimilarity observed in the achieved phenolic acids profile.

In the present study, the magnitude of the ergosterol content was: P. ostreatus $>A$. bisporus $>$ L. edodes, even though Barreira et al. [19] reported a different order-namely, A. bisporus $>$ L. edodes $>$ P. ostreatus - but these authors used Soxhlet extraction with a different solvent ( $n$-hexane).

\subsection{Bioactive Properties of the Mushroom Ethanolic Extracts}

\subsubsection{Anti-Inflammatory Activity}

The anti-inflammatory effects of the ethanolic extracts were assessed upon stimulation of RAW 264.7 macrophages with lipopolysaccharide for the production of the inflammatory mediator (NO). The most efficient species were A. bisporus and L. edodes, presenting the lowest $\mathrm{EC}_{50}$ values, followed by P. ostreatus (Table 2). The high activity exhibited by L. edodes extract may be related with its high content of protocatechuic acid, but without discarding the presence of other metabolites from different chemical classes such as terpenes, polysaccharides, and lipid metabolites that have also been reported as important contributors to the anti-inflammatory activity of mushroom extracts. The base cream was evaluated for anti-inflammatory activity and up to $800 \mu \mathrm{g} / \mathrm{mL}$, the base cream did not display activity.

The anti-inflammatory potential of different mushroom extracts has been described and related to its capacity to inhibit specific steps in the pathway leading to nuclear factor kappa B (NF- $\mathrm{kB}$ ) release [20]. Taofiq et al. [15] reported that P. ostreatus ethanolic extract had a better anti-inflammatory activity than $A$. bisporus but using a different extraction methodology (maceration).

\subsubsection{Anti-Tyrosinase Activity}

A. bisporus displayed the highest anti-tyrosinase activity among the studied mushroom species (Table 2). P. ostreatus and L. edodes exhibited very similar activities. Alam et al. [21] reported that the methanolic extract of $P$. ostreatus, at $0.125-1 \mathrm{mg} / \mathrm{mL}$, significantly inhibited tyrosinase activity up to $11.36 \%-59.56 \%$. To the author's best knowledge, there are no reports on the anti-tyrosinase activity of A. bisporus; nevertheless, Miyake et al. [22] described that 2-amino-3H-phenoxazin-3-one, a phenolic compound isolated from the fruiting body of this mushroom species, at $0.5 \mu \mathrm{M}$, significantly inhibited tyrosinase activity up to $80 \%$. Also, Yoon et al. [23] described that the methanolic extract of L. edodes at $0.125-1 \mathrm{mg} / \mathrm{mL}$, significantly inhibited tyrosinase activity by $15.12 \%-54.61 \%$. The base cream was evaluated for anti-tyrosinase activity and, up to $2 \mathrm{mg} / \mathrm{mL}$, the base cream did not inhibit tyrosinase enzyme.

Phenolic compounds have been reported to be responsible for the anti-tyrosinase activity of mushroom extracts, but Yan et al. [24] also isolated two steroidal triterpenes (betulin and trametenolic acid) from Inonotus obliquus (Ach. ex Pers.) Pilát and described their anti-tyrosinase activity. Betulin significantly inhibited tyrosinase activity with an $\mathrm{IC}_{50}$ of $5.13 \mu \mathrm{M}$, being even stronger than kojic acid $(6.43 \mu \mathrm{M})$ used as control, while trametenolic acid had an $\mathrm{IC}_{50}$ of $7.25 \mu \mathrm{M}$. The activity displayed by the studied mushroom extracts were related with the identified phenolic acids and ergosterol.

Tyrosinase is the rate-limiting enzyme in the melanin biosynthesis pathway where it converts tyrosine to dihydroxyphenylalanine (DOPA) and further oxidizes DOPA to dopaquinone [25]. Several factors such as exposure to UV radiation and release of $\alpha$-melanocyte-stimulating hormone trigger over-secretion of melanin from melanocytes causes hyperpigmentation [26]. Finding inhibitors of tyrosinase from natural sources is a topic of research interest and the studied mushroom extracts can be considered good candidates. 


\subsubsection{Antioxidant Activity}

A. bisporus and $P$. ostreatus showed the highest radical scavenging activity and reducing power (Table 2). The obtained results are consistent with the ones reported by Reis et al. [27], where A. bisporus methanolic extracts obtained by maceration gave the highest DPPH radical scavenging activity. Heleno et al. [28] reported that the reducing power of L. edodes methanolic extracts obtained by maceration revealed an $\mathrm{EC}_{50}$ of $3.19 \pm 0.03 \mathrm{mg} / \mathrm{mL}$, similar to the one reported in the present study. The base cream was also evaluated for antioxidant activity and, up $200 \mathrm{mg} / \mathrm{mL}$, the base cream did not display DPPH radical scavenging activity or reducing power.

Finding extracts or bioactive metabolites that display antioxidant activity seems to be one of the most important parameters in the design of cosmeceutical formulations, not just because they scavenge ROS but also because they are able to inhibit tyrosinase and matrix metalloproteinase enzymes responsible for hyperpigmentation and collagen degradation, respectively [29].

\subsubsection{Antibacterial Activity}

The resistance profiles to antibiotics of all tested bacteria strains are presented in Supplementary Materials for Gram negative and Gram positive bacteria. All the mushroom extracts showed antibacterial potential against MSSA and MRSA (Table 3). Regarding the Gram-positive bacteria strains, in general, L. edodes showed the highest activity against the tested bacteria presenting the lowest MIC values, while $A$. bisporus revealed the weakest activity presenting the highest MIC values against MSSA and MRSA and no activity against E. faecalis, P. ostreatus, and L. edodes showed antibacterial activity against $E$. faecalis. None of the extracts was able to inhibit the growth of Gram-negative bacteria strains, even at the highest tested concentration $(20 \mathrm{mg} / \mathrm{mL})$. These results are in agreement with the ones reported by Barros et al. [30] that described the absence of antibacterial activity of $A$. bisporus methanolic extracts against P. aeruginosa. Alves et al. [31] also reported no activity for A. bisporus against resistant P. aeruginosa and E. coli. However, Stojković et al. [9] reported antibacterial activity of this mushroom (methanolic and ethanolic extracts) against E. coli and P. aeruginosa, but this may be due to the fact that these authors used ATCC bacteria whereas, in the present work, all the bacteria are clinical isolates with antibiotics resistance profile. The base cream was evaluated for antibacterial activity and, up $200 \mathrm{mg} / \mathrm{mL}$, no activity was observed against all the tested bacteria.

Several authors have reported that the normal microflora of the skin include Staphylococcus epidermis, S. aureus, and P. aeruginosa, among others [32]. Taking into account that these microorganisms are opportunistic and have high resistance profiles, they are a threat when skin lesions occur, causing severe localized infections even with systemic invasion [33].

Thus, finding extracts/compounds with high antibacterial activity against these species can be considered beneficial in the design of cosmeceutical formulations. The mechanism of phenolic compounds' antibacterial activity has been attributed to its ability to interfere with the bacteria membrane causing their disruption and subsequent DNA damage [34].

\subsection{Chemical Profile and Bioactivity of the Final Cosmeceutical Formulations}

In the base creams incorporated with the extracts, the presence of phenolic acids, cinnamic acid, and ergosterol was monitored by HPLC-PDA. By analyzing Table 1, it can be concluded that all the target compounds were stable when incorporated in the base cream matrix. In fact, they were detected at almost the same amount as initially found in the extracts. It was possible to quantify in the final cosmeceutical formulations $85 \%-100 \%$ of the content quantified in the extracts before incorporation. The total phenolic acids found in A. bisporus, P. ostreatus, and L. edodes extract was $90.06 \pm 0.74,584.24 \pm 3.01$, and $142.81 \pm 2.39 \mu \mathrm{g} / \mathrm{g}$, respectively, while after incorporation in the base cosmetic cream, the total phenolic acids became $87.73 \pm 1.63,509.47 \pm 3.93$, and $119.61 \pm 2.54(\mu \mathrm{g} / \mathrm{g})$, respectively, suggesting that there was no significant loss of bioactive compounds. The same trend was observed for the ergosterol content in the mushroom extracts after incorporation. 
Table 1. Phenolic acids and ergosterol content in the mushroom ethanolic extracts and in the cosmeceutical formulations.

\begin{tabular}{|c|c|c|c|c|c|c|}
\hline \multirow{2}{*}{ Phenolic Acids ( $\mu \mathrm{g} / \mathrm{g}$ ) } & \multicolumn{3}{|c|}{ Mushroom Extracts } & \multicolumn{3}{|c|}{ Cosmeceutical Formulations } \\
\hline & A. bisporus & P. ostreatus & L.edodes & A. bisporus cream & P. ostreatus Cream & L. edodes Cream \\
\hline Cinnamic acid & $90.06 \pm 0.74^{\mathrm{b}}$ & $362.7 \pm 1.28^{\mathrm{a}}$ & $7.31 \pm 0.14^{\mathrm{c}}$ & $87.73 \pm 1.63^{b}$ & $317.43 \pm 1.32^{a}$ & $6.10 \pm 0.56^{c}$ \\
\hline 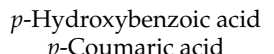 & nd & $\begin{array}{l}157.78 \pm 4.13 \\
63.74 \pm 0.15\end{array}$ & $83.05 \pm 2.15$ & nd & $138.88 \pm 2.30$ & $73.67 \pm 1.56$ \\
\hline $\begin{array}{l}p \text { p-coumaric acid } \\
\text { Protocatechuic acid }\end{array}$ & $\begin{array}{l}\text { na } \\
\text { nd }\end{array}$ & $\begin{array}{l}63.74 \pm 0.15 \\
\text { nd }\end{array}$ & $\begin{array}{c}\text { na } \\
52.45 \pm 0.38\end{array}$ & $\begin{array}{l}\text { nd } \\
\text { nd }\end{array}$ & $\begin{array}{c}53.16 \pm 2.94 \\
\text { nd }\end{array}$ & $\begin{array}{c}\text { nd } \\
39.85+1.53\end{array}$ \\
\hline Total $(\mu \mathrm{g} / \mathrm{g})$ & $90.06 \pm 0.74^{c}$ & $584.24 \pm 3.01^{\mathrm{a}}$ & $142.81 \pm 2.39^{\mathrm{b}}$ & $87.73 \pm 1.63^{c}$ & $509.47 \pm 3.93^{\mathrm{a}}$ & $119.61 \pm 2.54^{\mathrm{b}}$ \\
\hline Ergosterol (mg/g) & $44.79 \pm 0.37^{b}$ & $78.20 \pm 0.54^{a}$ & $8.94 \pm 0.04^{c}$ & $45.43 \pm 1.38^{\mathrm{b}}$ & $71.62 \pm 0.29^{\mathrm{a}}$ & $8.60 \pm 0.25^{c}$ \\
\hline
\end{tabular}

nd -not detected. In each row and within each group of samples (mushrooms extracts and final cosmeceutical formulations), different letters mean significant statistical differences $(p<0.05)$.

Table 2. Anti-inflammatory, anti-tyrosinase, and antioxidant activities of the mushroom ethanolic extracts and of the cosmeceutical formulations.

\begin{tabular}{|c|c|c|c|c|c|c|}
\hline \multirow{2}{*}{ Bioactivities } & \multicolumn{3}{|c|}{ Mushroom Extracts } & \multicolumn{3}{|c|}{ Cosmeceutical Formulations } \\
\hline & A. bisporus & P. ostreatus & L.edodes & A. bisporus Cream & P. ostreatus Cream & L.edodes Cream \\
\hline Anti-inflammatory $\left(\mathrm{EC}_{50}\right.$ value, $\mathrm{mg} / \mathrm{mL}$ ) & $0.18 \pm 0.01^{\mathrm{b}}$ & $0.29 \pm 0.03^{\mathrm{a}}$ & $0.16 \pm 0.01^{\mathrm{b}}$ & $2.52 \pm 0.23^{b}$ & $3.81 \pm 0.23^{\mathrm{a}}$ & $2.59 \pm 0.23^{b}$ \\
\hline $\begin{array}{l}\text { Anti-tyrosinase }\left(\mathrm{EC}_{50} \text { value, } \mathrm{mg} / \mathrm{mL}\right) \\
\text { Antioxidant }\left(\mathrm{EC}_{50} \text { value } \mathrm{mg} / \mathrm{mL}\right)\end{array}$ & $0.16 \pm 0.01^{\mathrm{b}}$ & $0.86 \pm 0.07^{a}$ & $0.82 \pm 0.08^{a}$ & $3.22 \pm 0.37^{b}$ & $11.01 \pm 0.35^{\mathrm{a}}$ & $11.89 \pm 0.85^{a}$ \\
\hline DPPH radical-scavenging activity & $7.04 \pm 0.32^{b}$ & $7.69 \pm 0.20^{b}$ & $23.36 \pm 1.11^{\mathrm{a}}$ & $234.3 \pm 10.9^{b}$ & $239.5 \pm 10.4^{\mathrm{b}}$ & $321.8 \pm 16.4^{\mathrm{a}}$ \\
\hline Reducing power & $2.34 \pm 0.05^{\mathrm{b}}$ & $2.36 \pm 0.08^{b}$ & $3.03 \pm 0.04^{\mathrm{a}}$ & $35.91 \pm 0.31^{\mathrm{b}}$ & $32.18 \pm 2.73^{c}$ & $48.90 \pm 0.64^{\mathrm{a}}$ \\
\hline
\end{tabular}

Dexamethasone was used as positive control for anti-inflammatory activity $\left(\mathrm{EC}_{50}=0.016 \mathrm{mg} / \mathrm{mL}\right.$ ). Ascorbic acid was used as positive control for anti-tyrosinase activity $\left(\mathrm{EC}_{50}=0.031 \mathrm{mg} / \mathrm{mL}\right)$. Trolox was used as positive control for antioxidant activity $\left(\mathrm{EC}_{50}=0.041 \mathrm{mg} / \mathrm{mL}\right.$ for reducing power and $0.042 \mathrm{mg} / \mathrm{mL}$ for $\mathrm{DPPH}$ scavenging activity. In each row and within each group of samples (mushrooms extracts and final cosmeceutical formulations), different letters mean significant statistical differences ( $p<0.05$ ).

Table 3. Antibacterial activity of the mushroom ethanolic extracts and of the cosmeceutical formulations (MIC values, $\mathrm{mg} / \mathrm{mL}$ ).

\begin{tabular}{ccccccc}
\hline \multirow{2}{*}{ Bacteria Strains } & \multicolumn{3}{c}{ Mushroom Extracts } & & \multicolumn{2}{c}{ Cosmeceutical Formulations } \\
\cline { 2 - 7 } & A. bisporus & P. ostreatus & L. edodes & A. bisporus Cream & P. ostreatus Cream & L. edodes Cream \\
\hline Gram-positive & & & & & & \\
Enterococcus faecalis & $>20$ & 10 & 5 & $>200$ & 200 & 50 \\
Methicillin sensitive Staphylococcus aureus & 10 & 2.5 & 2.5 & 200 & 50 & 50 \\
Methicillin resistant Staphylococcus aureus & 10 & 2.5 & 2.5 & $>200$ & $>200$ & $>200$ \\
Gram-negative & $>20$ & $>20$ & $>20$ & $>200$ & $>200$ & $>200$ \\
Escherichia coli & $>20$ & $>20$ & $>20$ & &
\end{tabular}


The anti-inflammatory, anti-tyrosinase, antioxidant, and antibacterial activities of the final cosmeceutical formulations were also evaluated and the results are given in Table 2. The final formulations incorporated with A. bisporus and L. edodes showed the highest anti-inflammatory activity like it was observed with the individual ethanolic extracts; while $P$. ostreatus presented the lowest anti-inflammatory potential. The cosmeceutical formulation incorporated with $A$. bisporus extract revealed the highest anti-tyrosinase, while $P$. ostreatus and $L$. edodes revealed the lowest one, also in agreement with the individual activity of the extracts before incorporation. A. bisporus and P. ostreatus cream formulations showed the highest antioxidant activity, while L. edodes presented the lowest DPPH scavenging activity and reducing power.

All the cosmeceutical formulations showed inhibition against MSSA and MRSA (Table 3). A. bisporus cream formulation revealed the lowest activity for MSSA and MRSA, and did not present activity against $E$. faecalis. L. edodes cream formulation showed the highest activity against E. faecalis, MSSA, and MRSA. The cosmeceutical formulations displayed antibacterial activity against the same bacteria species that were inhibited by the extracts.

All the bioactivities were affected when extracts were incorporated into the cream formulations, increasing the $\mathrm{EC}_{50}$ values to higher concentrations, but still displaying all the bioactivities evaluated and maintaining the levels of the analyzed bioactive compounds. This increase in the $\mathrm{EC}_{50}$ values can be due to some interferences of the base cream that may affect the extract availability to exert the same bioactivity. Considering the antioxidant and the antibacterial activities exhibited by the final cream formulations, mushroom extracts can also act as preservatives in the final formulations.

\section{Materials and Methods}

\subsection{Standards and Reagents}

Acetonitrile 99.9\% was of high-performance liquid chromatography (HPLC) grade from Lab-Scan (Lisbon, Portugal), methanol was of analytical grade and supplied by Pronalab (Lisbon, Portugal). 2,2-Diphenyl-1-picrylhydrazyl (DPPH) was obtained from Alfa Aesar (Ward Hill, MA, USA). Dulbecco's modified Eagle's minimum essential medium (DMEM), fetal bovine serum (FBS), penicillin, streptomycin, Griess reagent system (Promega), DMSO, sulphorodamine B (SRB), lipopolysaccharide (LPS), 3,4-dihydroxy-L-phenylalanine (L-DOPA), and mushroom tyrosinase enzyme were obtained from Sigma-Aldrich Co. (Saint Louis, MO, USA). The culture media Muller Hinton broth (MHB) and Tryptic Soy Broth (TSB) were obtained from Biomerieux (Marcy l'Etoile, France). Blood agar with 7\% sheep blood and Mac Conkey agar plates were purchased from Biomerieux Marcy l'Etoile, France). The dye $p$-iodonitrotetrazolium chloride (INT) was purchased from Sigma-Aldrich (Spruce Street; St. Louis, MO, USA) and was used as microbial growth indicator.

\subsection{Mushroom Species and Preparation of the Ethanolic Extracts}

Fresh samples of Agaricus bisporus (J.E.Lange) Imbach, Lentinula edodes (Berk.) Pegler, and Pleurotus ostreatus (Jacq. ex Fr.) P. Kumm) were purchased from a local supermarket in the Northeast of Portugal. For each mushroom species, the fruiting bodies were dried at $30{ }^{\circ} \mathrm{C}$ in an oven, reduced to a fine powder (20 mesh) and the treated portions mixed together to obtain homogeneous samples for further use.

To obtain the extracts, $3.0 \mathrm{~g}$ of the dried powder was mixed with $150 \mathrm{~mL}$ of ethanol and extracted in a Soxhlet apparatus for $4 \mathrm{~h}$ (12 cycles). Finally, the solvent was evaporated under reduced pressure (rotary evaporator Büchi R-210, Flawil, Switzerland) to obtain the dried ethanolic extracts [35]. 


\subsection{Chemical Characterization of the Extracts}

\subsubsection{Analysis of Phenolic Acids}

Dried extracts were re-dissolved in a water/ethanol mixture $(80: 20, v / v)$ at a concentration of $20 \mathrm{mg} / \mathrm{mL}$ and filtered through a $0.22 \mu \mathrm{m}$ nylon disposable filter. The Shimadzu 20A series ultra-fast liquid chromatograph (UFLC, Shimadzu Corporation, Kyoto, Japan), operating at $0.5 \mathrm{~mL} / \mathrm{min}$ and equipped with a Waters Spherisorb S3 ODS2 C18 column $(3 \mu \mathrm{m}, 150 \times 4.6 \mathrm{~mm})$ thermostatted at $35^{\circ} \mathrm{C}$, was used for phenolic acids identification and quantification. A binary solvent mixture consisting of $0.1 \%$ formic acid in water (A) and acetonitrile (B) was used. The detection was performed using a photodiode array detector (PDA) at $280 \mathrm{~nm}$ as the preferred wavelength [27]. The phenolic acids were quantified using calibration curves obtained from commercial standards, namely: protocatechuic acid $\left(y=164741 x ; R^{2}=0.999\right), p$-hydroxybenzoic acid $\left(y=113523 x ; R^{2}=0.999\right), p$-coumaric acid $\left(y=433521 x ; R^{2}=0.998\right)$, and cinnamic acid $\left(y=583527 x ; R^{2}=0.998\right)$. The results were expressed as $\mu \mathrm{g}$ per $\mathrm{g}$ of extract.

\subsubsection{Analysis of Ergosterol}

Each dried mushroom extract was re-dissolved in methanol at a final concentration of $10 \mathrm{mg} / \mathrm{mL}$ and filtered through a $0.22 \mu \mathrm{m}$ nylon disposable filter. The ergosterol identification and quantification was performed in HPLC-UV equipment, an integrated system composed by a pump (Knauer, Smartline system 1000, Berlin, Germany), a degasser system (Smartline manager 5000), an auto-sampler (AS-2057 Jasco, Easton, MD, USA), and a UV detector (Knauer Smartline 2500) according to a methodology developed in-house [19]. Chromatographic separation was achieved with an Inertsil 100A ODS-3 reversed-phase column $(5 \mu \mathrm{m}, 4.6 \times 150 \mathrm{~mm}$, BGB Analytik AG, Boeckten, Switzerland) operating at $35^{\circ} \mathrm{C}$ (7971R Grace oven). The mobile phase was acetonitrile/methanol (70:30, $\left.v / v\right)$ and detection was performed at $280 \mathrm{~nm}$. Ergosterol was quantified using a calibration curve obtained from a commercial standard $\left(y=0.71727 x+0.20476 ; R^{2}=0.99624\right)$. The results were expressed as $\mathrm{mg}$ per $\mathrm{g}$ of extract.

\subsection{Evaluation of the Anti-Inflammatory Activity}

Anti-inflammatory activity was evaluated following the procedure reported by Taofiq et al. [15]. Briefly, the RAW 264.7 macrophage cell line is cultured in DMEM medium and supplemented with $10 \%$ heat-inactivated fetal bovine serum, glutamine, and antibiotics at $37{ }^{\circ} \mathrm{C}$ under $5 \% \mathrm{CO}_{2}$, in humidified air. For each experiment, cells were detached with a cell scraper to achieve a cell density of $5 \times 10^{5}$ cells $/ \mathrm{mL}$. Trypan blue dye exclusion test was used to estimate the proportion of dead cells that were found to be less than 5\%. Cells were seeded in 96-well plates at 150,000 cells/well and allowed to stay overnight for proper attachment to the plate. Then, cells were treated with extract solutions (concentration of $400-50 \mu \mathrm{g} / \mathrm{mL}$, for each extract) for $1 \mathrm{~h}$. Dexamethasone $(50 \mu \mathrm{M})$ was used as a positive control. Then, macrophage cells with the extract were stimulated with LPS $(1 \mu \mathrm{g} / \mathrm{mL})$ for a period of $18 \mathrm{~h}$. The effect of all the tested samples in the absence of LPS was also evaluated, in order to observe if they induced changes in nitric oxide (NO) basal levels. In negative controls, no LPS was added. The extracts and LPS were dissolved in supplemented DMEM.

Each ethanolic extract was dissolved in 50\% DMSO at $8 \mathrm{mg} / \mathrm{mL}$ and submitted to successive dilutions (400 to $50 \mu \mathrm{g} / \mathrm{mL}$ ). Griess reagent System kit which contains sulphanilamide, $N$-(1-napthyl) ethylenediamine hydrochloride (NED), and nitrite solutions was used to quantify nitric oxide. A reference curve of nitrite (sodium nitrite $100 \mu \mathrm{M}$ to $1.6 \mu \mathrm{M} ; y=0.0065 x+0.1309 ; R^{2}=0.9988$ ) was prepared in a 96-well plate. The cell culture supernatant $(100 \mu \mathrm{L})$ was transferred to the plate and mixed with sulphanilamide and NED solutions, 5-10 min each, at room temperature. The produced nitric oxide was determined by measuring the absorbance at $540 \mathrm{~nm}$ (microplate reader ELX800 Biotek, Bio-Tek Instruments, Inc.; Winooski, VT, USA), and compared with the standard calibration curve. $\mathrm{EC}_{50}$ values were calculated from the graph reporting the percentage inhibition of NO production versus extract concentration. 


\subsection{Evaluation of the Anti-Tyrosinase Activity}

Each ethanolic extract was dissolved in 50\% DMSO at $10 \mathrm{mg} / \mathrm{mL}$ and submitted to successive dilutions (10 to $0.625 \mathrm{mg} / \mathrm{mL}$ ). Tyrosinase inhibition assay was performed using L-DOPA as substrate according to the procedure described by Yoon et al. [36] with slight modifications. The assays were carried out in a 96-well microplate with each well containing $40 \mu \mathrm{L}$ of the sample, $80 \mu \mathrm{L}$ of phosphate buffer (0.1 M, pH 6.8), $40 \mu \mathrm{L}$ of tyrosinase enzyme (60 units $/ \mathrm{mL})$, and $40 \mu \mathrm{L}$ of L-DOPA (3.5 mM). The mixture was incubated for $10 \mathrm{~min}$ at $37{ }^{\circ} \mathrm{C}$, and the absorbance measured at $475 \mathrm{~nm}$ using a microplate reader (ELX800 Bio-Tek Instruments, Inc.). L-ascorbic acid was used as the positive control and the results were compared with a control comprising 50\% DMSO in place of the sample. The percentage of tyrosinase inhibition was calculated as follows: $\left[\left(\mathrm{A}_{\text {control }}-\mathrm{A}_{\text {sample }}\right) / \mathrm{A}_{\text {control }}\right] \times 100$. $\mathrm{EC}_{50}$ values were calculated from the calibration curve tyrosinase inhibition percentage versus extract concentration.

\subsection{Evaluation of the Antioxidant Activity}

\subsubsection{Reducing Power}

Each ethanolic extract was dissolved in ethanol at $50 \mathrm{mg} / \mathrm{mL}$ and submitted to successive dilution (50 mg/mL to $1.56 \mathrm{mg} / \mathrm{mL})$. The extract solutions with the different concentrations $(0.5 \mathrm{~mL})$ were mixed with sodium phosphate buffer $(200 \mathrm{mmol} / \mathrm{L}, \mathrm{pH} 6.6,0.5 \mathrm{~mL})$ and potassium ferricyanide $(1 \%$ $w / v, 0.5 \mathrm{~mL})$. The mixture was incubated at $50{ }^{\circ} \mathrm{C}$ for $20 \mathrm{~min}$, followed by addition of trichloroacetic acid $(10 \% w / v, 0.5 \mathrm{~mL})$. Then, $0.8 \mathrm{~mL}$ of the mixture was transferred to a 48 -well plate, followed by addition of deionized water $(0.8 \mathrm{~mL})$, ferric chloride $(0.1 \% w / v, 0.16 \mathrm{~mL})$ and the absorbance measured at $690 \mathrm{~nm}$ in the Microplate Reader mentioned above [37]. The sample concentration providing 0.5 of absorbance ( $E_{50}$ values) was calculated from the calibration curve absorbance $(690 \mathrm{~nm})$ versus extract concentrations. Trolox was used as positive control.

\subsubsection{DPPH Scavenging Activity}

The prepared ethanolic extracts were dissolved in ethanol at $50 \mathrm{mg} / \mathrm{mL}$ and successive dilutions $(50 \mathrm{mg} / \mathrm{mL}$ to $1.56 \mathrm{mg} / \mathrm{mL})$ were made. For the reaction mixture, $30 \mu \mathrm{L}$ of each extract solution and $270 \mu \mathrm{L}$ of methanol containing DPPH radicals $\left(6 \times 10^{-5} \mathrm{~mol} / \mathrm{L}\right)$ were added. The mixture was allowed to stand in the darkness for $1 \mathrm{~h}$. The absorbance was further measured at $515 \mathrm{~nm}$ in the Microplate Reader mentioned above [37]. The radical scavenging activity (RSA) was calculated using the equation: $\%$ RSA $=\left[\left(A_{D P P H}-A_{S}\right) / A_{D P P H}\right] \times 100$, where $A_{S}$ is the absorbance of the sample solution with the sample and $\mathrm{A}_{\mathrm{DPPH}}$ is the absorbance of the DPPH solution. The concentrations responsible for $50 \%$ of RSA ( $\mathrm{EC}_{50}$ values) were calculated from the graphs of RSA percentages versus extract concentrations. Trolox was used as positive control.

\subsection{Evaluation of the Antibacterial Activity}

\subsubsection{Bacteria Strains}

As multiresistant bacteria are more problematic due to their resistance to a wide range of antibiotics, clinical isolates were used instead of ATCC bacteria. Therefore, bacteria strains correspond to clinical isolates obtained from patients hospitalized in various departments at the Hospital Center of Trás-os-Montes and Alto Douro (Vila Real, Portugal). Two Gram-negative bacteria (Escherichia coli (isolated from urine), and Pseudomonas aeruginosa (isolated from expectoration)) and three Gram-positive bacteria (Enterococcus faecalis (isolated from urine), methicillin-sensitive Staphylococcus aureus (MSSA) (isolated from wound exudate), and methicillin-resistant Staphylococcus aureus (MRSA) (isolated from expectoration)) were tested. All the tested bacteria were placed to grow in the appropriate fresh medium, $24 \mathrm{~h}$, and kept in the oven at $37^{\circ} \mathrm{C}$ before analysis in order to maintain the exponential growth phase. 


\subsubsection{Characterization of the Antibiotic Susceptibility of the Bacteria Strains}

Microorganism identification and susceptibility tests were performed using MicroScan panels (MicroScan ${ }^{\circledR}$; Siemens Medical Solutions Diagnostics, West Sacramento, CA, USA) by microdilution plate method. The interpretation criteria were based on Interpretive Breakpoints as indicated in Clinical and Laboratory Standards Institute (CLSI) [38]; Committee of L'Antibiogramme de la Société Française de Microbiologie (CA-SFM) [39]; and in the European Committee on Antimicrobial Susceptibility Testing (EUCAST) [40].

\subsubsection{Determination of the Minimal Inhibitory Concentration (MIC)}

Each ethanolic extract was dissolved in $50 \%$ DMSO at $220 \mathrm{mg} / \mathrm{mL}$. The determination of the minimal inhibitory concentration (MIC) was performed by the microdilution method and the rapid $p$-iodonitrotetrazolium chloride (INT) colorimetric assay according to [41] with some modifications. Initially, $50 \mu \mathrm{L}$ of the extract solution in $50 \% \mathrm{DMSO}$ at $220 \mathrm{mg} / \mathrm{mL}$ was added to $450 \mu \mathrm{L}$ of medium TSB or MHB, according to the bacteria requirements, making a solution of $22 \mathrm{mg} / \mathrm{mL}$ at $5 \% \mathrm{DMSO}$. Then, $190 \mu \mathrm{L}$ of this extract solution was added to each well of the 96-well microplate and therefore submitted to successive dilutions over the wells containing $90 \mu \mathrm{L}$ of MHB or TSB media, starting by taking $100 \mu \mathrm{L}$ of the higher concentration to the right below one and thus repeating this procedure sequentially. Afterwards, $10 \mu \mathrm{L}$ of inoculum $\left(1.5 \times 10^{8} \mathrm{CFU} / \mathrm{mL}\right)$ was added to all the microplate wells thus achieving a concentration range of 20 to $0.156 \mathrm{mg} / \mathrm{mL}$. Three negative controls were prepared (one with MHB/TSB 5\% DMSO, another one with the extract, and the third one with medium and antibiotic). For the Gram negative bacteria, colistin was used at a concentration based on the obtained MIC (Table S1, Supplementary Materials); for the Gram positive bacteria, vancomycin was used (Table S2, Supplementary Materials). A positive control was also performed with MHB/TSB medium at $5 \%$ DMSO and the inoculum. The plates were then incubated at $37^{\circ} \mathrm{C}$, for $24 \mathrm{~h}$, in an oven (Jouan, Berlin, Germany). The MIC of the samples was determined after adding INT $(0.2 \mathrm{mg} / \mathrm{mL}, 40 \mu \mathrm{L})$ and after incubation at $37^{\circ} \mathrm{C}$ for $30 \mathrm{~min}$. Viable microorganisms reduced the yellow dye to a pink color. MIC was defined as the lowest extract concentration that prevented this change, thus showing complete inhibition of bacterial growth.

\subsection{Development of the Cosmeceutical Formulations Based on Mushroom Extracts}

The cosmetic cream used in this study is a commercial base cream purchased from Fagron Iberica S.A.U. (Barcelona, Spain). It is described as a bright, white to yellowish color; free from fragrances, colorants, parabens, mineral oils, sodium lauryl sulphate (SLS), propylene glycol, and ethoxylates; and composed of purified water, $\mathrm{O} / \mathrm{W}$ emulsifiers, emollient, lubricant, pro-liposome, vitamin E, chelating agents, silicone, and preservatives. According to the supplied technical data, all ingredients are recognized as safe by the US Food and Drug Administration (FDA), Regulation (EC) No 1907/2006-REACH and the National Health Surveillance Agency (ANVISA) of Brazil. Considering the MIC values for the antibacterial activity, the highest ones were observed for A. bisporus and P. ostreatus, $(\sim 10 \mathrm{mg} / \mathrm{mL})$. For L. edodes, the highest $\mathrm{EC}_{50}$ value was found for the antioxidant activity $(\sim 25 \mathrm{mg} / \mathrm{mL})$. In order to cover all the bioactivities and considering the dilutions necessary to carry out the assays, the base creams were incorporated with $10 \times$ MIC value for A. bisporus and P. ostreatus and $10 \times \mathrm{EC}_{25}$ value for L. edodes, which correspond to a scale of $100 \mathrm{mg}$ of extract per gram of base cream. The base-cream and the extract were carefully mixed to guarantee sample homogeneity and analyzed immediately after incorporation to study the ability of the extracts to maintain their bioactivities in the cosmetic base cream.

The final cream formulations were extracted with methanol for $30 \mathrm{~min}$, filtered, dried in a rotary evaporator, and re-dissolved in a water:methanol mixture $(80: 20, v / v)$ at $20 \mathrm{mg} / \mathrm{mL}$ for phenolic acids analysis; in methanol at $10 \mathrm{mg} / \mathrm{mL}$ for ergosterol analysis; in $50 \%$ DMSO at $200 \mathrm{mg} / \mathrm{mL}$ for anti-inflammatory activity evaluation; in 50\% DMSO at $200 \mathrm{mg} / \mathrm{mL}$ for anti-tyrosinase activity evaluation; in $100 \%$ DMSO at $200 \mathrm{mg} / \mathrm{mL}$ for antioxidant activity evaluation; and in $5 \%$ DMSO at $220 \mathrm{mg} / \mathrm{mL}$ for antibacterial activity evaluation. 


\subsection{Statistical Analysis}

For all the experiments, three independent samples were prepared and all the assays were carried out in triplicate. The results are expressed as mean values \pm standard deviation (SD). The differences between the samples were analyzed using one-way analysis of variance (ANOVA) followed by Tukey's honestly significant difference post hoc test with $\alpha=0.05$, coupled with Welch's statistic. This treatment was carried out using IBM SPSS Statistics for Windows version 23.0 program (IBM Corp., Armonk, NY, USA).

\section{Conclusions}

Based on the above findings, it can be concluded that ethanolic extracts of A. bisporus, P. ostreatus, and $L$. edodes own strong antioxidant activity which suggest that they have the ability to cope with oxidative stress promoting ROS generation and acting as skin anti-aging. The extracts revealed antibacterial activity against MSSA and MRSA, which are microorganisms found to colonize the skin during injury and inflammation. After incorporating the extracts into the base cosmetic cream, the mushroom cosmetic formulations still display antioxidant and anti-inflammatory activity by inhibition of NO production and melanin by suppression of tyrosinase activity. Furthermore, the final cosmeceutical formulations containing the mushroom extracts were found to inhibit important bacteria strains responsible for skin damage. These diverse functions displayed by the mushroom extracts-before and after incorporation in the base cream formulations-suggest that mushrooms contain sustainable bioactive compounds that can be the basis of cosmeceutical formulations capable to tackle skin aging, inflammation, and hyperpigmentation. Hence, studies in dermal and epidermal cells should be conducted in order to clarify the role of the compounds responsible for the assessed bioactive properties. Further studies are currently being conducted regarding the evaluation of the stability of the cosmeceutical formulations.

Supplementary Materials: Supplementary materials can be accessed at: http://www.mdpi.com/1420-3049/21/ 10/1372/s1.

Acknowledgments: The authors are grateful to the Foundation for Science and Technology (FCT, Portugal) and FEDER for CIMO (UID/AGR/00690/2013), LSRE (Project UID/EQU/50020/2013) and for financial support to S.A.H. (SFRH/BPD/101413/2014), R.C.C. (BPD/68344/2010), and L.B. (BPD/107855/2015). A.M.G.-P. is also thankful to the Spanish MINECO/FEDER for financial support through the project AGL2015-64522-C2-2-R.

Author Contributions: S.A.H., I.C.F.R.F. and M.F.B. designed the experiments; O.T. performed all the experimental assays with collaboration of R.C.C. in the cytotoxicity and anti-inflammatory assays, M.J.A. in the anti-bacterial assays and S.A.H., and L.B. in chemical analyses; O.T. and I.C.F.R.F. wrote the manuscript; M.F.B. and A.M.G.-P. revised the manuscript.

Conflicts of Interest: The authors declare no conflict of interest.

\section{References}

1. Papakonstantinou, E.; Roth, M.; Karakiulakis, G. Hyaluronic acid: A key molecule in skin aging. Dermato-Endocrinology 2012, 4, 253-258. [CrossRef] [PubMed]

2. Leem, K.H. Effects of Olibanum extracts on the collagenase activity and procollagen synthesis in Hs68 human fibroblasts and tyrosinase activity. Adv. Sci. Technol. Lett. 2015, 88, 172-175.

3. Yadav, T.; Mishra, S.; Das, S.; Aggarwal, S.; Rani, V. Anticedants and natural prevention of environmental toxicants induced accelerated aging of skin. Environ. Toxicol. Pharmacol. 2015, 39, 384-391. [CrossRef] [PubMed]

4. Gündoğdu, A.; Kılıç, H.; Ulu-Kılıç, A.; Kutateladze, M. Susceptibilities of multidrug-resistant pathogens responsible for complicated skin and soft tissue infections to standard bacteriophage cocktails. Mikrobiyol. Bulteni 2016, 2, 215-223. [CrossRef]

5. Tamsyn, S.A.T.; Pauline, H.; Declan, P.N. Anti-collagenase, anti-elastase and anti-oxidant activities of extracts from 21 plants. BMC Complement. Altern. Med. 2009, 9, 1-11.

6. Soto, M.L.; Falqué, E.; Domínguez, H. Relevance of natural phenolics from grape and derivative products in the formulation of cosmetics-Review. Cosmetics 2015, 2, 259-276. [CrossRef] 
7. Taofiq, O.; González-Paramás, A.M.; Martins, A.; Barreiro, M.F.; Ferreira, I.C.F.R. Mushrooms extracts and compounds in cosmetics, cosmeceuticals and nutricosmetics-A review. Ind. Crops Prod. 2016, 90, $38-48$. [CrossRef]

8. Kamarudzaman, A.N.; Chay, T.C.; Amir, A.; Talib, S.A. Biosorption of Mn(II) ions from Aqueous Solution by Pleurotus Spent Mushroom Compost in a Fixed-Bed Column. Procedia Soc. Behav. Sci. 2015, 195, 2709-2716. [CrossRef]

9. Stojković, D.; Reis, F.S.; Glamočlija, J.; Ćirić, A.; Barros, L.; van Griensven, L.J.L.D.; Ferreira, I.C.F.R.; Soković, M. Cultivated strains of Agaricus bisporus and A. brasiliensis: Chemical characterization and evaluation of antioxidant and antimicrobial properties for final healthy product-Natural preservatives in yoghurt. Food Funct. 2014, 5, 1602-1612. [CrossRef] [PubMed]

10. Baba, E.; Uluköy, G.; Öntaş, C. Effects of feed supplemented with Lentinula edodes mushroom extract on the immune response of rainbow trout, Oncorhynchus mykiss, and disease resistance against Lactococcus garvieae. Aquaculture 2015, 448, 476-482. [CrossRef]

11. Cheah, I.K.; Halliwell, B. Ergothioneine: Antioxidant potential, physiological function and role in disease. Biochim. Biophys. Acta 2012, 1822, 784-793. [CrossRef] [PubMed]

12. Zembron-Lacny, A.; Gajewski, M.; Naczk, M.; Siatkowski, I. Effect of shiitake (Lentinus edodes) extract on antioxidant and inflammatory response to prolonged eccentric exercise. J. Physiol. Pharmacol. 2013, 64, 249-254. [PubMed]

13. Mizuno, M.; Nishitani, Y.; Hashimoto, T.; Kanazawa, K. Different suppressive effects of fucoidan and lentinan on IL-8 mRNA expression in in vitro gut inflammation. Biosci. Biotechnol. Biochem. 2009, 3, 2324-2325. [CrossRef] [PubMed]

14. Fernandes, A.; Barros, L.; Martins, A.; Herbert, P.; Ferreira, I.C.F.R. Nutritional characterisation of Pleurotus ostreatus (Jacq. ex Fr.) P. Kumm. Produced using paper scraps as substrate. Food Chem. 2015, 169, 396-400. [CrossRef] [PubMed]

15. Taofiq, O.; Calhelha, R.C.; Heleno, S.A.; Barros, L.; Martins, A.; Santos-Buelga, C.; Queiroz, M.J.R.P.; Ferreira, I.C.F.R. The contribution of phenolic acids to the anti-inflammatory activity of mushrooms: Screening in phenolic extracts, individual parent molecules and synthesized glucuronated and methylated derivatives. Food Res. Int. 2015, 76, 821-827. [CrossRef]

16. Stefan, R.I.; Vamanu, E.; Angelescu, G.C. Antioxidant activity of crude methanolic extracts from Pleurotus ostreatus. Res. J. Phytochem. 2015, 9, 25-32.

17. Facchini, J.M.; Alves, E.P.; Aguilera, C.; Gern, R.M.M.; Silveira, M.L.L.; Wisbeck, E.; Furlan, S.A. Antitumor activity of Pleurotus ostreatus polysaccharide fractions on Ehrlich tumor and Sarcoma 180. Int. J. Biol. Macromol. 2014, 68, 72-77. [CrossRef] [PubMed]

18. Carneiro, A.A.; Ferreira, I.C.F.R.; Dueñas, M.; Barros, L.; da Silva, R.; Gomes, E.; Santos-Buelga, C. Chemical composition and antioxidant activity of dried powder formulations of Agaricus blazei and Lentinus edodes. Food Chem. 2013, 138, 2168-2173. [CrossRef] [PubMed]

19. Barreira, J.C.M.; Oliveira, M.B.P.P.; Ferreira, I.C.F.R. Development of a novel methodology for the analysis of ergosterol in mushrooms. Food Anal. Methods 2014, 7, 217-223. [CrossRef]

20. Taofiq, O.; Martins, A.; Barreiro, M.F.; Ferreira, I.C.F.R. Anti-inflammatory potential of mushroom extracts and isolated metabolites. Trends Food Sci. Technol. 2016, 50, 193-210. [CrossRef]

21. Alam, N.; Yoon, K.N.; Lee, K.R.; Shin, P.G.; Cheong, J.C.; Yoo, Y.B.; Shim, M.J.; Lee, M.W.; Lee, U.Y.; Lee, T.S. Antioxidant activities and tyrosinase inhibitory effects of different extracts from Pleurotus ostreatus fruiting bodies. Mycobiology 2010, 38, 295-301. [CrossRef] [PubMed]

22. Miyake, M.; Yamamoto, S.; Sano, O.; Fujii, M.; Kohno, K.; Ushio, S.; Iwaki, K.; Fukuda, S. Inhibitory effects of 2-amino-3H-phenoxazin-3one on the melanogenesis of murine B16 melanoma cell line. Biosci. Biotechnol. Biochem. 2010, 74, 753-758. [CrossRef] [PubMed]

23. Yoon, K.N.; Alam, N.; Lee, J.S.; Lee, K.R.; Lee, T.S. Detection of phenolic compounds concentration and evaluation of antioxidant and antityrosinase activity of various extract from Lentinus edodes. World Appl. Sci. J. 2011, 12, 1851-1859.

24. Yan, Z.F.; Yang, Y.; Tian, F.H.; Mao, X.X.; Li, Y.; Li, C.T. Inhibitory and acceleratory effects of Inonotus obliquus on tyrosinase activity and melanin formation in B16 melanoma cells. Evid. Based Complement. Altern. Med. 2014. [CrossRef] [PubMed] 
25. Meng, T.X.; Zhang, C.F.; Miyamoto, T.; Ishikawa, H.; Shimizu, K.; Ohga, S.; Kondo, R. The melanin biosynthesis stimulating compounds isolated from the fruiting bodies of Pleurotus citrinopileatus. J. Cosmet. Dermatol. Sci. Appl. 2012, 2, 151-157.

26. Ali, S.A.; Choudhary, R.K.; Naaz, I.; Ali, A.S. Understanding the Challenges of Melanogenesis: Key role of bioactive compounds in the treatment of hyperpigmentory disorders. J. Pigment. Dis. 2015, 2, 1-9.

27. Reis, F.S.; Martins, A.; Barros, L.; Ferreira, I.C.F.R. Antioxidant properties and phenolic profile of the most widely appreciated cultivated mushrooms: A comparative study between in vivo and in vitro samples. Food Chem. Toxicol. 2012, 50, 1201-1207. [CrossRef] [PubMed]

28. Heleno, S.A.; Ferreira, R.C.; Antonio, A.L.; Queiroz, M.J.R.P.; Barros, L.; Ferreira, I.C.F.R. Nutritional value, bioactive compounds and antioxidant properties of three edible mushrooms from Poland. Food Biosci. 2015, 11, 48-55. [CrossRef]

29. Masaki, H. Role of antioxidants in the skin: Anti-aging effects. J. Dermatol. Sci. 2010, 58, 85-90. [CrossRef] [PubMed]

30. Barros, L.; Cruz, T.; Baptista, P.; Estevinho, L.M.; Ferreira, I.C.F.R. Wild and commercial mushrooms as source of nutrients and nutraceuticals. Food Chem. Toxicol. 2008, 46, 2742-2747. [CrossRef] [PubMed]

31. Alves, M.J.; Ferreira, I.C.F.R.; Martins, A.; Pintado, M. Antimicrobial activity of wild mushroom extracts against clinical isolates resistant to different antibiotics. J. Appl. Microbiol. 2012, 115, 466-475. [CrossRef] [PubMed]

32. Rodrigues, F.; Palmeira-de-Oliveira, A.; das Neves, J.; Sarmento, B.; Amaral, M.H.; Oliveira, M.B. Medicago spp. extracts as promising ingredients for skin care products. Ind. Crops Prod. 2013, 49, 634-644. [CrossRef]

33. Russo, A.; Concia, E.; Cristini, F.; de Rosa, F.G.; Esposito, S.; Menichetti, F.; Petrosillo, N.; Tumbarello, M.; Venditti, M.; Viale, P.; et al. Current and future trends in antibiotic therapy of acute bacterial skin and skin-structure infections. Clin. Microbiol. Infect. 2016, 22, 27-36. [CrossRef]

34. Martins, N.; Barros, L.; Henriques, M.; Silva, S.; Ferreira, I.C.F.R. In vivo anti-candida activity of phenolic extracts and compounds: Future perspectives focusing on effective clinical interventions. BioMed Res. Int. 2015, 247382, 1-14.

35. Heleno, S.A.; Diz, P.; Prieto, M.A.; Barros, L.; Rodrigues, A.; Barreiro, M.A.; Ferreira, I.C.F.R. Optimization of ultrasound-assisted extraction to obtain mycosterols from Agaricus bisporus L. by response surface methodology and comparison with conventional Soxhlet extraction. Food Chem. 2016, 197, 1054-1063. [CrossRef] [PubMed]

36. Yoon, K.N.; Alam, N.; Lee, K.R.; Shin, P.G.; Cheong, J.C.; Yoo, Y.B.; Lee, T.S. Antioxidant and antityrosinase activities of various extracts from the fruiting bodies of Lentinus lepideus. Molecules 2011, 16, 2334-2347. [CrossRef] [PubMed]

37. Fernandes, A.; Barreira, J.C.M.; Antonio, A.L.; Oliveira, M.B.P.P.; Martins, A.; Ferreira, I.C.F.R. Effects of gamma irradiation on chemical composition and antioxidant potential of processed samples of the wild mushroom Macrolepiota procera. Food Chem. 2014, 149, 91-98. [CrossRef] [PubMed]

38. Performance Standards for Antimicrobial Susceptibility Testing; CLSI Document M100-S18; Clinical and Laboratory Standards Institute: Wayne, PA, USA, 2008.

39. Comité de L'Antibiogramme de la Société Française de Microbiologie; Communiqué; Société Française de Microbiologie: Paris, France, 2012.

40. European Committee on Antimicrobial Susceptibility Testing (EUCAST); European Society of Clinical Microbiology and Infectious Diseases (ESCMID): Stockholm, Sweden, 2013.

41. Kuete, V.; Ango, P.Y.; Fotso, G.W.; Kapche, G.D.; Dzoyem, J.P.; Wouking, A.G.; Ngadjui, B.T.; Abegaz, B.M. Antimicrobial activities of the methanol extract and compounds from Artocarpus communis (Moraceae). BMC Complement. Altern. Med. 2011, 25, 11-42. [CrossRef] [PubMed]

Sample Availability: Mushroom samples are available from the authors. 